NASA Technical Memorandum 105949

AIAA-93-1338

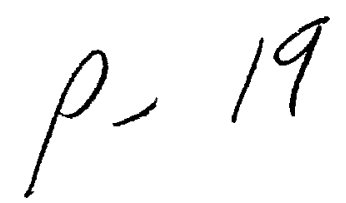

\title{
The Application of Structural Reliability Techniques to Plume Impingement Loading of the Space Station Freedom Photovoltaic Array
}

Isam S. Yunis and Kelly S. Carney

Lewis Research Center

Cleveland, Ohio

Prepared for the

34th Structures, Structural Dynamics, and Materials Conference cosponsored by the AIAA, ASME, ASCE, AHS, and ASC

LaJolla, California, April 19-21, 1993

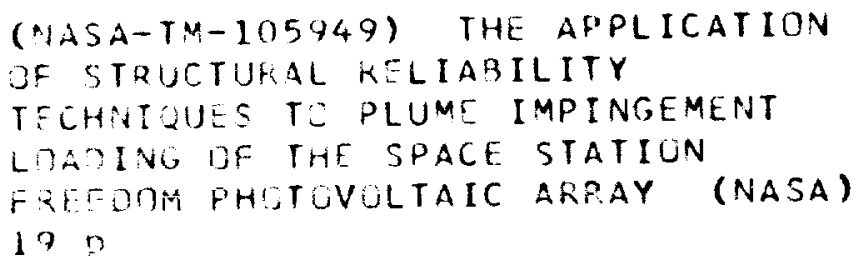


THE APPLICATION OF STRUCTURAL RELIABILITY TECHNIQUES TO PLUME I APINGEMENT

\title{
LOADING OF THE SPACE STATION FREEDOM PHOTOVOLTAIC ARRAY
}

\author{
Isam S. Yunis and Kelly S. Carney \\ National Aeronautics and Space Administration \\ Lewis Research Center \\ Cleveland, Ohio 44135
}

\begin{abstract}
A new aerospace application of structural reliability techniques is presented, where the applied forces depend on many probabilistic variables. This application is the plume impingement loading of the Space Station Freedom Photovoltaic Arrays. When the space shuttle berths with Space Station Freedom it must brake and maneuver towards the berthing point using its primary jets. The jet exhaust, or plume, may cause high loads on the photovoltaic arrays. The many parameters governing this problem are highly uncertain and random. An approach, using techniques from structural reliability, as opposed to the accepted deterministic methods, is presented which assesses the probability of failure of the array mast due to plume impingement loading. A Monte Carlo simulation of the berthing approach is used to determine the probability distribution of the loading. A probability distribution is also determined for the strength of the array. Structural reliability techniques are then used to assess the array mast design. These techniques are found to be superior to the standard deterministic dynamic transient analysis, for this class of problem. The results show that the probability of failure of the current array mast design, during its 15 year life, is minute.
\end{abstract}

\section{Introduction}

There exists a class of civil structures which have a wide variety of uncertain loadings and are difficult to test at a system level, but must still possess a long life with minimal risk of failure. At the same time, these structures must not be excessively expensive or weighty. Because of the rendom character of the uncertainties in both the loading and the capability of these structures, a probabilistic approach to design is warranted. The probabilistic discipline of structural reliability has been developed in order to ensure safety and consistency in structural designs and in the civil engineering design codes. ${ }^{1-2}$ Recently, structural reliability techniques have also been applied to aerospace engineering components, such as the turbopump blades of the space shuttle main engine. ${ }^{3.5}$ Here, the random variables of concern have focused on the constitutive relationships and properties of the structure. In this study, a new aerospace applica- tion of structural reliability techniques is presented, where the applied forces as well as the structure depend on many probabilistic variables. This application is the plume impingement loading of the Space Station Freedom Photovoltaic Arrays.

When the space shuttle approaches Space Station Freedom it must brake and maneuver to come to a complete stop relative to Space Station Freedom. This is achieved through the use of the shuttle's primary reaction control system (PRCS) jets, each of which delivers about $800 \mathrm{lb}$ of force. The plume from these jets expands quickly in space so that a low density plume impinges upon the photovoltaic (PV) arrays (Fig. 1). However, since the area of the photovoltaic arrays is so large (110 ft by $39 \mathrm{ft}$, Fig. 2), the small plume forces can cause significant loading in the photovoltaic array. Of particular concern is the bending moment at the base of the mast, which can be very large because of the mast's long length.

Calculating the exact transient loads which result from plume impingement forcing is quite difficult because of the many random variables which govern the analysis. These random variables are the shuttle position, the shuttle orientation, the space station orientation, space station thermal deformation, photovoltaic array mast twist, feathered angle accuracy, predicted plume forces accuracy, the dynamics excited by a particular approach to Space Station Freedom (essentially dynamic load factor), modeling uncertainty, and the array mast strength uncertainty. Most of these variables define the geometric orientation of the space shuttle with respect to Space Station Freedom and, therefore, define the amount of plume exhaust impinging upon the arrays.

All of these random variables are independent and it is highly unlikely that all of their worst case values would coincide in time. Nonetheless, a set of transient dynamic analyses are currently performed, using forcing functions which are selected in an attempt to bound the worst possible applied forces. The resulting internal loads are compared to the limit load capability of the structure. Results from the referenced work indicates that at the permanently manned configuration (PMC, Fig. 1), the bending moment applied to photovoltaic 
array mast exceeds the limit load by 10 percent. This attempt to bound the worst possible loading has been made the baseline for structural design.

This study demonstrates the use of structural reliability techniques to compute the probability of failure of the array masts, with loading governed by random inputs and an uncertain structural capability. The probability of failure during a single shuttle berthing approach to PMC and during the lifetime of the arrays will be presented. This work will be important in deciding whether or not the worat case deterministic transient analysis discussed above is appropriate. This work lays the foundations for a plume impingement analysis methodology that is probability based and one that produces a realistic, and still reasonably conservative, loads assessment. A cost analysis based on the probability of failure is also presented.

Although plume impingement loading is a concern for the entire space station, this study focuses on the bending moment in the PV array masts. In particular, the arrays on the port side (Fig. 1) are emphasized because they are the most heavily loaded. The methodology developed is useful for these arrays, and for all plume impingement loads analyses and stage configurations of the space station.

\section{Theoretical Overview}

Two methods of performing probability analysis are presented. The first is conventional Monte Carlo simulation which produces a probability distribution for an output, based upon statistical trials of a sequence of random vectors. This method is easily implemented, unfortunately, it requires a large number of simulations to accurately predict the output probability distribution. The second method presented is a first-order secondmoment scheme introduced by Hasofer and Lind. ${ }^{6}$ This method uses the probability distributions of the random variables in the limit state function to produce the probability of failure. In addition to the probability subjects presented, system reliability and cost analysis are briefly discussed.

\section{Monte Carlo Simulation}

Monte Carlo simulation is based upon running many simulations of a system with random variable inputs and determining the distribution or probability of an output. In the case of building a distribution for an output, each of the input variables is varied randomly according to its probability distribution function and input into the simulation. The random output is then recorded. This process is repeated many times until a distribution for the output can be accurately defined. This method has grown increasingly popular in recent years with the advances in computational speed, but the number of simulations required to build an accurate distribution of the output can be very large. In addition, any change to any of the input variables requires that the entire analysis be redone. The benefit of the method is its simplicity.

For the case of using Monte Carlo simulation to determine the probability of an output failing, a failure function muat be defined. Consider the limit state (failure) function, $g=R-S$ where $R$ is the resistance (strength) and $S$ is the load. Then, if $g<0(S>R)$ the output fails and if $g>0(S<R)$ the output survives. The limit state function $\mathrm{g}$ has a binomial distribution and the number of failures divided by the total simulations is the probability of failure, or more generally,

$$
\left.P_{i}=\int I[g(x)] f(x) d x \approx i \sum g_{i}\right) / N
$$

where $I[g(x)]$ is an indicator function such that $I=1$ if $g<0$ and $I=0$ if $g \geq 0, f(x)$ is the probability density of the inputs, and $N$ is the number of simulations. As indicated above, this method is easy to implement, but the number of simulations required can be very large. This is especially true if the probability of failure is low, since very few of the simulations will be failures. The approximate variance on $P_{f}$ in Eq. (1) is given by

$$
\operatorname{Var}\left[P_{t}\right]=P_{t, \text { actual }}\left(1-P_{f, \text { actual }}\right) / N
$$

To properly define a probability of $P_{f}$ will take at least four orders of magnitude more simulations than $1 / P_{t}$ in order to achieve a coefficient of variation less than 1 percent. Therefore, for $P_{1}=10^{-3}(\sim 3 \sigma), 10^{7}$ simulations are needed to get the coefficient of variation of $P_{f}$ to less than 1 percent. Note that Eq. (2) is not a practical formula since $P_{f, \text { actual }}$ is not known.

\section{First-Order Second-Moment Methods}

These methods are called first-order methods because they use the first-order term of a Taylor's series expansion to approximate the mean and the standard deviation (second moment) of the limit state function. They differ from the Monte Carlo approaches in that each variable within the limit state function is represented only by its distribution, mean, and standard deviation. The distributions of random variables are utilized to yield the probability of failure. The Hasofer-Lind method $^{6}$ gives, with respect to the limit state function, 
an invariant definition of the safety index and the probability of failure. In the Hasofer-Lind method, each variable is transformed to a reduced coordinate with a zero mean and unit variance. The safety index becomes the minimum distance from the origin to the limit state in the space of reduced coordinates. A detailed description of this method is beyond the scope of this paper and is contained in several excellent references. $1,2,6$ In general, the solution to this problem must be found using a computer program. In this study, the algorithm presented by Rackwitz and Fiessler is used. ${ }^{7}$

The limitation of this method is in the use of only the first and second moments. This method is exact if the distribution of the limit state function is Gaussian since a Gaussian distribution can be completely specified by its mean and variance. If the distribution of the limit state function is not Gaussian, then other moments are required to completely specify the distribution. In this case, second moment methods provide only approximations to the probability of failure.

\section{System Reliability}

Practical engineering problems almost always have more than one failure mode. Each failure mode may be represented by a particular limit state function and, therefore, have a particular probability of failure, $P_{f i}$. Each of these component probabilities must be combined to yield a system probability of failure. ${ }^{8}$ For a system which is represented as a series, failure of any component is considered to be a failure of the entire system. When a series system has no correlation between the failure modes, the system probability of failure ${ }^{1}$ is given by

$$
P_{f}=1-\Pi\left(1-P_{f i}\right)
$$

When a series system has correlation in its modes of failure, its probability of failure is lower. Therefore, the above equation represents an upper bound on the probability of failure and is conservative.

\section{Cost Analysis}

Once the probability of failure is defined, cost analysis may be performed to optimize a design. Cost may be defined in many ways. However, the total cost, $\mathrm{C}_{\mathrm{T}}$ is the most logical. Total cost should encompass initial costs, $\mathrm{C}_{1}$, and the cost of failure, $\mathrm{C}_{\mathrm{F}}$. Initial costs include design, manufacturing, and construction costs. The cost of failure can be more difficult to define or even nebulous if loss of life or status are considered. However, a cost must be associated with each conse- quence of a failure. Given $C_{1}$ and $C_{F}$ the total cost of a design is given by,

$$
\mathrm{C}_{\mathrm{T}}=\mathrm{C}_{\mathrm{I}}+\mathrm{P}_{\mathrm{f}} * \mathrm{C}_{\mathrm{F}}
$$

Note that $\mathrm{C}_{\mathrm{F}}$ is multiplied by the probability of failure to account for the fact that $C_{F}$ may never be required.

The optimum design is found by minimizing $\mathrm{C}_{\mathrm{T}}$. The curve of $C_{T}$ will always be concave up if an increase in $C_{I}$ causes a decrease in $P_{f}$ Therefore a minimum will exist.

\section{Methodology}

Because of the complicated laws of physics governing jet exhaust in a vacuum, it was not practical to include the necessary equations of the problem physics in the limit state functions. Therefore, the conventional Monte Carlo approach was chosen to create the applied plume load distributions (denoted by $\mathbf{S}$ ). Distribution functions of the photovoltaic array strength, and uncertainty factors for plume physics and array dynamics were also derived (denoted by $R$ and $U$, respectively). This problem has multiple failure modes and limit state functions. To avoid repeating the large number of calculations required in Monte Carlo analysis for each failure mode, the Hasofer-Lind second-moment method was used to calculate the probability of failure from the load and strength distributions. The form of the nonnormalised limit state function used in this analysis was

$$
\begin{aligned}
\mathbf{g}=\mathbf{R}_{\text {mast }} & -U_{\text {plume }} * U_{\text {dynamic }} \\
& *\left(S_{\text {nominal }}+S_{\text {breakout }}\right)
\end{aligned}
$$

A description of how the mean and variance of the variables in Eq. (5) were determined follows.

\section{Monte Carlo Calculation of Loads Distribution}

Previous loads analyses indicate that the port inboard arrays are the ones critically loaded by plume impingement. Therefore, this study will focus on these two arrays: PIU (port inboard upper) and PIL (port inboard lower) (Fig. 1). These arrays are in their optimal feathering position, which is defined as the location of the $\alpha$ and $\beta$ joints that minimize the plume impingement loads. Figure 1 shows the arrays in their feathered orientations.

Two different shuttle maneuvers were considered independently: the nominal approach and the NormZ 
breakout. The nominal approach is a series of different jet firings as the shuttle brakes and maneuvers towards the berthing point. Most of the firings are attitude adjustments, but the Z-braking (not to be confused with the NormZ breakout maneuver) and Y-burn sideways firings are frequent and impinge greatly on the PV arrays. Therefore, only these two firings were considered to contribute to the loading of the arrays during a nominal approach.

The second maneuver of importance is the NormZ breakout, which is a long duration NormZ firing used to generate an opening velocity between the shuttle and Space Station Freedom during an abort of the approach. This maneuver is restricted to the last $75 \mathrm{ft}$ of the approach.

Now consider the distributions of the input variables beginning with shuttle position and orientation with respect to Space Station Freedom. During a nominal approach, the Z-braking jets can only be fired within $75 \mathrm{ft}$ of the space station and the Y-burn has little impact outside this distance, so the distribution of shuttle distance away from Space Station Freedom is assumed such that 99.9 percent of the firings take place within $75 \mathrm{ft}$ of the space station. Even though the Zbraking jets are not supposed to be used outside $75 \mathrm{ft}$, there is a possibility they will be fired so this 0.1 percent chance is held open by the distribution. The shape of the distribution is defined by the braking profile. If the shuttle pilots braked at a constant rate then the probability of being at a certain position would grow linearly, with more time spent nearer the space station, but because the pilots tend to brake more towards the end, an exponential curve was used (Fig. 3). Because of the faster speeds at $75 \mathrm{ft}$, the shuttle is less likely to be there than at $10 \mathrm{ft}$. The distance the shuttle is away from the space station is one random variable input.

A NormZ breakout can only occur within the final $75 \mathrm{ft}$, but again the possibility is left open that one will be performed outside this range. However, unlike the nominal approach, it is also assumed that the pilots may get into trouble outside $75 \mathrm{ft}$ and hold until $75 \mathrm{ft}$ in order to perform the high authority NormZ breakout. Therefore a spike is placed on the breakout distance distribution (Fig. 4) such that 10 percent of the breakouts occur at $75 \mathrm{ft}$.

As the shuttle approaches the berthing point it should remain within a $10^{\circ}$ half angle cone originating from the berthing point and expanding along the line of approach. The shuttle is uniformly likely to be anywhere within this cone, and it is assumed that there is a 5 percent chance that the pilots will exceed the limits of the cone and that the likelihood of being a distance outside the cone decreases linearly to zero (Fig. 5). For the nominal approach, one other restriction is applied: Only the port half of the cone is used since the shuttle will only fire towards the port side if it is on the port side. The position of the shuttle within the cone of operations is two random variables: Distance from the cone centerline and the angle on the cone.

The shuttle orientation is maintained by a digital autopilot which has $\pm 2^{\circ}$ deadband, which means that the shuttle can temporarily reach maximum rotations larger than $\pm 2^{\circ}$. It is assumed that the distribution of shuttle orientation about any of its three axes is normal and that the deadband is at $2 \sigma$ on a normal distribution (Fig. 6). With this distribution, there is a 0.1 percent chance that the shuttle will exceed $\pm 3^{\circ}$ of rotation. The orientation of the shuttle with respect to Space Station Freedom is three random variables: $X, Y$, and $\mathrm{Z}$ shuttle rotations.

The space station orientation is maintained by an automatic control system of control moment gyros with backup by a reaction control system. Since the control authority of these are low, it is not clear that Space Station Freedom can remain within its deadbands of $\pm 1^{\circ}$. Therefore, the deadband is considered to be the $1 \sigma$ position on a normal distribution (Fig. 7 ). This makes the distribution of the three space station axes identical to that of the shuttle (Fig. 6). The orientation of the space station is three random variables: $\mathrm{X}, \mathrm{Y}$, and $\mathrm{Z}$ space station rotations.

As the space station orbits the Earth it undergoes thermal deformations as different sides are lighted. Early indications are that the deformation may be as large as $\pm 5^{\circ}$ from the center to the end of the truss. This is the maximum about each axis. The likelihood of a particular deformation is given by a normal distribution with $5^{\circ}$ as the $3 \sigma$ deviation (Fig. 8). The thermal deformation of Space Station Freedom is three random variables: $X, Y$, and $Z$ space station truss distortions.

Also considered is the design tolerance on the array mast tip twist. Specifications state that this may be up to $3^{\circ}$. This twist is assumed to be normally diatributed about the perfect design with $3^{\circ}$ being the $3 \sigma$ deviation (Fig. 9). The mast tip twist is one random variable.

There is approximately 30 percent $^{9}$ uncertainty in the current equations ${ }^{10}$ used to derive plume impingement forces. To include this uncertainty in the analysis, another random variable representing this uncertainty is multiplied to the dynamic results. This factor is modeled as being normally distributed about 1.0 with a standard deviation of 0.1 (Fig. 10). In this way the plume physics is treated as one random variable. 
As mentioned earlier, the PV arrays are being feathered to minimize plume impingement loads. However, this is not dynamic feathering, so one position for the $\alpha$ and $\beta$ joints has been found and these angles are held during the entire approach. There is some uncertainty in these angles due to many factors, among which are the possible joint locking locations, uncertainty about the on-orbit position of the joints, and dynamic twisting. Therefore, the feather angles cannot be guaranteed to be perfect, so a distribution is assumed. The designers suggest that the $3 \sigma$ values are $\pm 4^{\circ}$ for the $\alpha$ joint and $\pm 3^{\circ}$ for the $\beta$ joint. The normal distributions used for the $\alpha$ and $\beta$ joint angles are shown in Figs. 11 to 13 about their feather positions (shown in Fig. 1). The feather angle uncertainties are two input random variables: $\alpha$ and $\beta$ rotations.

The dynamics of the arrays are the most difficult of all the random variables to quantify. Ideally, a large database of shuttle approach firings could be used to run dynamic response as part of the simulation process, however, lacking a database of shuttle approaches, some assumptions needed to be made about the firing time histories and their associated dynamic load factors (DLF's). An estimate was made of what the 3 $\sigma$ DLF is for each firing. From the data, an estimate was also made for the variance of the $3 \sigma$ firing about the expected value. The numbers are different for each of the arrays and are shown in Figs. 14 to 16. For the nominal approach, the dynamic response is dominated by the Y-burns, so much so that the Y-burn is the only firing that effects the PIU array. Because of this, on the PIU array the DLF due to the Y-burns is shown in Fig. 14 and the DLF on the Z-braking firings is zero. On the PIL array, much of the load is due to the forces actually impinging upon the PIU array and dynamic coupling. Because of this, the DLF for the Y-burn on the PIL array (Fig. 15) is applied to the Y-burn forces on the PIU array. The DLF due to the Z-braking firings (Fig. 16) is applied to the Z-braking firings on the PIL array itself. Array dynamics are two input random variables: Y-DLF and Z-DLF.

For the NormZ breakout the DLF's change to those shown in Figs. 17 and 18 . In this case, the bulk of the plume impinges upon the PIL array and because of dynamic coupling, the DLF's are both applied to the forces on the PIL array.

The finite element model used to generate the dynamic response and the DLF's has an uncertainty associated with it. This uncertainty is estimated to be \pm 20 percent. This modeled as a normally distributed random variable with a mean of 1.0 and a standard deviation of 0.0667 (Fig. 19).
Photovoltaic Array Strength Distrioution

The Space Station Freedom Photovoltaic Array consists of four major elements, which are shown in Fig. 2. The first is a center deployable truss or mast, the primary load bearing element of the system. Next, there is a canister where the mast is stored during launch. It also provides a transition structure on orbit. Third are the blankets upon which solar cells are mounted. The final component is the blanket boxes which protect the blankets during launch. The blanket boxes are mounted off of the top of the mast and the canister, and once deployed, support the tensioned blankets. It is the tension which supplies the structural bending stiffness to the blankets. The dynamics of this configuration have been studied in detail. ${ }^{11}$

The element of the photovoltaic array which is the most critical for loads is the mast. The cause of this criticality is the mast's long length. Even a small load applied onto the blankets is transferred, through the top blanket boxes, onto the top of the mast. This small force causes a large moment at the base of the mast. The mast itself is a folding truss with four longerons (Fig. 20). There are battens and other components which hold the longerons together. Because of its deployability, there are additional components which make the mast a complicated structure, as is illustrated in Fig. 21.

Despite the fact that the array mast is complex, its primary failure mechanism is classical Euler buckling of the longeron, ${ }^{12}$ as is shown in Fig. 22. When the entire mast is placed into bending about its neutral axis, the moment forces longerons into compression and tension (Fig. 23). When the bending is in a plane $45^{\circ}$ from the face of the mast, then, in each bay, two longerons are in the neutral plane, one is in tension, and one is in compression. If the compression load due to bending exceeds the Euler buckling load, $P_{c r}$, that longeron will then buckle. It is the buckling of the longerons in compression that defines the design limit load of the entire mast. The plane $45^{\circ}$ from the face is weakest plane of the mast. For bending in the plane of the face of the mast, the mast is $\sqrt{2}$ times stronger. The reason for this is that there are two longerons taking load in compression while the distance from the neutral axis to the longerons is reduced by $\sqrt{2}$.

Any longeron in compression throughout the entire length of the mast may fail, but the applied load is greatest at the base and decreases in each bay up the length of the mast. The probability of failure must be calculated for each longeron. These failure modes are independent and so the mast may be represented as a 
series system. The overall probability of failure is then calculated using Eq. (3).

It should be noted that failure modes other than longeron buckling exist in the photovoltaic array mast. These failure modes were not considered at this time. The required design information to analyze these failure modes in detail was not available. It is known, however, that these failure modes have higher critical loads than the critical load for longeron buckling.

When a single longeron buckles the entire system does not fail catastrophically. For example, it takes two longerons to fail in any bay for catastrophic failure to occur. When considering that the longeron strength is a random variable, the probability of this mode of failure will be much lower than that of one longeron buckling. Even though it is not a catastrophic failure, one longeron buckling was still considered to be system failure. The reason for this definition is that if one longeron fails the array may not be able to be re-stowed for on-orbit replacement. This would drastically complicate EVA operations, and would have mission success and safety implications. Therefore, because this definition is conservative and consistent with the Space Station Freedom program specifications, one longeron buckling was defined as system failure and the mast becomes, in effect, a series system.

The distribution of the array strength is assumed to be log-normal, although no fabrication data is available at this time to confirm this selection. However, this sssumption is consistent with structures whose members are inspected. ${ }^{1}$ Discarding the obviously defective members truncates the left hand tail of the strength distribution. In the case of the photovoltaic array, the lognormal distribution is especially appropriate because of the extensive inspections and testing which will be performed on mast components. The mean strength is assumed to be the calculated buckling load multiplied by an empirical knockdown factor. The variance was calculated by assuming that the project defined safety factors bound the $3 \sigma$ standard deviation mast strength and using the definitions of the log-normal probability distribution. ${ }^{13}$ It is worth noting that the empirical factors used in the aerospace industry to define a structural design limit load ${ }^{14}$ are roughly equivalent to the $-3 \sigma$ strength based on a probability distribution.

\section{$\underline{\text { Results }}$}

\section{$\underline{\text { Load Distribution }}$}

The nominal and NormZ breakout load distributions were computed separately based on 100,000 Monte Carlo simulations. The resulting distributions of the weak axis moments are shown in Figs. 24 to 27. In these figures, the data points are the results of the simulations and the curves are the distributions used to model the data. These parameters of the distributions are detailed in Table 1. The type of distribution was determined by plotting the results on normal and log-normal distribution paper. The breakont maneuvers produced lognormal distributions and surprisingly the right sides of the nominal approach produced normal distributions.

The distributions chosen for the nominal approach only match the right side of the data because of the odd shape of the data. This odd shape is due to the fact that at about $20 \mathrm{ft}$ out, the shuttle is edge on to the PIU array. Therefore, there are many points at which the Y-burn loads on the array are near zero. Inside of $20 \mathrm{ft}$, the Y-burn plumes one face of the arrays and outside of $20 \mathrm{ft}$ the Y-burn plumes the other face. This crossover effect makes it impossible to match a standard distribution to the results. However, this should not effect the results significantly since the right side of the curve will dominate the probability of failure analysis and this side of the curve matches the data well.

\section{Strength Distribution}

Three mast designs were considered, each of which represents three discrete designs of the Space Station Freedom Photovoltaic Array. The design limit loads of the three masts analyzed were $8300,30,700$, and 48,500 in.-lb. The calculated means and coefficients of variation for these three masts are shown in Table 2. A plot of the strength distribution of the 48,500 in.-lb mast is shown in Fig. 28. This is the current space station photovoltaic array mast design. The PIU and the PIL mast were given the same distribution.

\section{Probability of Failure and System Reliability}

The probability of failure of each longeron in both the PIU and the PIL photovoltaic arrays was calculated. For the two specific cases of the bottom longerons of the 30,700 in.-lb PIL and PIU arrays, the design points, variable sensitivity, and probability of failures are shown in Tables 3 and 4. The probability that any longeron, in either the PIU mast or the PIL mast would fail, was calculated using Eq. (3). As discussed previously, this equation is applicable when there is no correlation in the strength of the longerons. Since there is almost certainly some correlation in the strength of the longeron members, using Eq. (3) is conservative. At this time, no correlation data is available, and so a conservative approach is warranted. 
The probability of failure of either array mast over the entire life of Space Station Freedom was also computed. It was assumed that a breakout would occur on every approach, which is likely very conservative, but no data exists upon which to make a better assumption. The total number of approaches to Space Station Freedom over its entire life will be about 120 . The lifetime probability is given by,

$$
P_{f}=1-\left(1-P_{f, \text { event }}\right)^{120}
$$

Table 5 summarizes the system probabilities of failure calculated. The probability of failure ranges from an almost certainty in the case of the 8300 in.-lb array to almost zero in the case of the 48,500 in.-lb array, the current design. The exact numerical values for $P_{f}$, given in Table 5, are not accurate when these values are extremely small. There are two reasons for this inaccuracy. First, an insufficient number of Monte Carlo simulations were performed to accurately define the load distribution in the extreme tail region (as noted by Eq. (2)). Secondly, the Hasofer-Lind method with the Rackwitz-Fiessler algorithm is not accurate in the extreme tail regions. ${ }^{2}$ In spite of this, these values are so low, in the case of the current design, that an exact value for $P_{f}$ is not relevant. As discussed in previous sections, many uncertainties remain in these analyses. However, where an uncertainty existed, a conservative assumption or parameter value was used. Therefore, photovoltaic array mast failure due to plume impingement, with the current design, is highly unlikely.

As a comparison, deterministic analyses have shown that an array mast of 33,000 in.-lb would be required to insure no photovoltaic array mast failures. Yet, this work shows that the probability of failure of the 30,700 in.-lb mast is approximately 0.0012 percent. A failure of a 33000 in.-lb mast would require approximately a $4.2 \sigma$ event. Therefore, the deterministic transient analysis, with bounding worst case force assumptions, does not give a clear picture of the risk involved with these particular designs.

\section{Sensitivity Analysis}

A result available from the Rackwitz and Fiessler algorithm is the sensitivity $(\alpha)$ of the design point, and hence the probability of failure, to the random variables. A high $\alpha$ indicates that the variable is important to the design point while a low $\alpha$ indicates that the variable is not important in the probability of failure.

In this analysis there were five random variables used in the Rackwitz and Fiessler algorithm (Eq. (5)):
Nominal plume load, NormZ breakout plume load, plume physics uncertainty, modeling uncertainty, and PV array strength. Tables 3 and 4 show the sensitivity of the probability of failure of the 30700 in.-lb PIU and PIL arrays to these random variables. As we would expect, the array strength is always important. On the load side, note that the PIL array is dominated by the NormZ breakout load. On the PIU array there is no clearly dominant variable but the nominal load is the most important and the model uncertainty factor is the least important. These sensitivity results suggest that effort and money should be spent increasing the strength or reducing the loads and not reducing the uncertainty factors.

\section{Cost Analysis}

The values cited here are relative and are shown more to illustrate the techniques involved in cost analysis, rather than to present precise project cost information. Let the original initial cost be simply $\mathrm{C}_{0}$. To increase the strength of the mast from 8300 to 30,700 in.-lb cost approximately $0.025 \mathrm{C}_{0}$. The redesign which increased the strength of the mast to 48,500 in.-lb cost approximately $0.02 \mathrm{C}_{0}$. These data points are plotted in Fig. 29 (normalized by $\mathrm{C}_{0}$ ).

The cost of failure was also estimated. A scenario was created which would yield a conservative cost estimate for the failure involved. Because single longeron buckling was used as the failure point, which is not a catastrophic failure, a catastrophic scenario was not created. The scenario developed, therefore, assumed single longeron buckling. If this longeron buckled it would be likely that an elbow or corner fitting would also fail. If this occurred, array retraction might not be possible. Since the photovoltaic arrays are to be replaced periodically, when their solar cells wear out, part of the replecement process consists of retracting the old arrays, and returning them to Earth in the space shuttle. There would be a cost associated with a complicated array retrieval. An estimate for this cost is $2.5 \mathrm{C}_{0}$, although this cost is not based upon $\mathrm{C}_{0}$. The probability of failure of each array was multiplied by the cost of failure to identify the expected cost of failure. A plot of these values is shown in Fig. 29 (normalized by $\mathrm{C}_{0}$ ). Finally, these sets of values were added together to compute total normalized cost using Eq. (4), and were also plotted in Fig. 29. Assuming that total cost minimization is the design criteria, then based upon the approximate data used, the 30,700 in.-lb array would appear to be the optimal design. 


\section{Suggested Developments}

This study is a demonstration of structural reliability techniques to unique application. However, the simplifying assumptions made prohibit the results from being utilised as more then information. In order to make these techniques more useful, several changes are suggested. These include considering dynamic transient analysis, considering variance reduction techniques, using better algorithms, and considering other failure modes.

In order to progress from this initial study to a more realistic and acceptable reliability assessment, actual dynamic analysis needs to be performed. There are two constraints to employing Monte Carlo simulation to do this. First, dynamic analysis requires so much computation that the resources most likely would not be available to run the required number of simulations to properly define the load distribution. Secondly, shuttle simulations are difficult to develop so that, at best, a few hundred simulated approaches to Space Station Freedom would be available.

The above limitations would place so much uncertainty on the Monte Carlo simulation results that they would not be useful. However, in recent years variance reduction techniques have been developed to make the Monte Carlo process converge more quickly to the true probability of failure. One of these methods is known as importance sampling. Importance sampling involves modifying Eq. (1) such that $g(x)$ is less than zero more often than would naturally occur based on $P_{f}$. This is done by sampling $x$ more frequently near the critical values. The probability of failure can then be written as,

$$
\begin{aligned}
& P_{f}=\int I[g(x)] f(x) p(x) / p(x) d x \\
& \approx\left(\sum g_{i}\right) * f(x) /[p(x) * N]
\end{aligned}
$$

where $p(x)$ is a probability density function centered around the failure point. This method can reduce the number of simulations required by several orders of magnitude over direct Monte Carlo. ${ }^{15}$

As additional design information about the photovoltaic array becomes available, the additional higher failure modes such as batten collapse should be considered. It is possible to represent these higher modes as a series system, with no correlation with longeron buckling failure modes. This would require a series of independent analyses. Consideration of catastrophic system failure, which would be a combination of different failure modes, would be much more complicated than consider- ing higher buckling modes. This analysis would no longer be a series of independent analyses. ${ }^{10}$ Both the probability of failure and system reliability analyses would need to be revised. Finally, as statistical information about the mast component fabricating becomes available, it should be included in formulating the strength distribution of the mast.

Limitations in the Rackwitz-Fiessler algorithm have been discussed. Any future work should utilize a first order-second moment algorithm with improved accuracy in the tail regions.

\section{Conclusions}

A methodology has been presented for examining internal loads on a structure when the applied forces are dependent on many random variables. It is applicable when the dependence of the loading on these random variables is not easily defined. This method places, as is standard in structural reliability analysis, the question of internal loads in terms of a probability of failure rather than a limit load exceedance. This methodology has been successfully applied to plume impingement loading from the space shuttle jets on the Space Station Freedom Photovoltaic Array. This method is also suitable to plume impingement loading on other components of the Space Station Freedom, as well as other large space structures subject to shuttle approaches. This probability based approach has been shown to be viable and could be developed as a more appropriate alternative to deterministic analysis of plume impingement.

Using the many conservative assumptions discussed in the paper, it was shown that the probability of failure of the Space Station Freedom Photovoltaic Array mast in bending due to plume impingement is very low. A large caveat must be issued. The design, operations, and specifications of the Space Station Freedom are still evolving. Changes in these items can have a large impact on the validity of the previous conclusion. Two previous array mast designs were also examined. The original design of the array mast had a high probability of failure, and an intermediate design had a low probability of failure.

\section{Acknowledgment}

The authors wish to extend their thanks and appreciation to Dr. Fred Moses of Case Western Reserve University who provided valuable advice concerning this work. This work was partially supported by the Space Station Freedom Project Office at the NASA Lewis Research Center. 
References

1. Melchers, R.E., Structural Reliability Analysis and Prediction, John Wiley \& Sons, New York, 1987.

2. Wirsching, P., Ortiz, K., and Lee, S.: "An Overview of Reliability Methods in Mechanical and Struetural Design," Structures, Structural Dynamics and Materials Conference, 28th, AIAA, New York, 1987, pp. 260-267.

3. Newell, J., Rajagopal, K., and Ho, H., “Probabilistic Structural Analysis of Space Propulsion System Turbine Blades," Structures, Structural Dynamics and Materials Conference, 30th, AIAA, New York, 1989, pp. 1860-1868.

4. Millwater, H., and Wu, Y.: "Structural Reliability Analysis Using a Probabilistic Finite Element Program," Structures, Structural Dynamics and Materials Conference, 30th, AIAA, New York, 1989, pp. 1846-1851.

5. Chamis, C.C.: "Probabilistic Structural Analysis Methods for Space Propulsion System Component," NASA TM-88861, 1986.

6. Hasofer, A., and Lind, N.: "Exact and Invariant Second-Moment Code Format, Journal of the Engineering Mechanics Division, Vol. 100, Feb. 1974, pp. 111-121.

7. Rackwitz, R., and Fiessler, B., "Structural Reliability Under Combined Random Load Sequences,"
Computers and Structures, Vol. 9, No. 5, 1978, pp. 489-494.

8. Moses, F.: "System Reliability Developments in Structural Engineering," Structural Safety, Elsevier Scientific, Amsterdam, Netherlands, 1982, pp. 3-13.

9. Lazaron, M.P., and Alred, J.W.: "Results of the SPAS-01 RCS Plume Impingement Test," AIAA Paper 85-0407, Jan. 1985.

10. Rayos, E.M., "RCS Plume Forces (RCSForce) Program," User's Manual, Johnson Space Center, Houston, TX, Sept. 21, 1988.

11. Carney, K., and Shaker, F.: "Free-Vibration Characteristics and Correlation of a Space Station SplitBlanket Solar Array," NASA TM-101452, 1989.

12. Timoshenko, S., and Gere, J.: Theory of Elastic Stability, McGraw-Hill, New York, 1961.

13. Miller, I., and Freund, J.: Probability and Statistics for Engineers, Second Ed., Prentice-Hall, NJ, 1977.

14. Peery, D.J., and Azar, J.J.: Aircraft Structures, McGraw-Hill, New York, 1982.

15. Fu, G., Verma, D., and Moses, F.: "Advanced Simulation Methods in System Reliability," Computational Mechanics of Probabilistic Reliability Analysis, edited by W. K. Liu and T. Belytschenko, Elmepress International, Lausanne, Switserland, 1990, pp. 232-245.

TABLE 1.-PARAMETERS FOR PHOTOVOLTAIC

ARRAY LOAD DISTRIBUTIONS

\begin{tabular}{|l|c|c|c|}
\hline Distribution & Type & $\begin{array}{c}\text { Mean, } \\
\text { in.-lb }\end{array}$ & $\begin{array}{c}\text { Coefficient of } \\
\text { variation, } \\
\text { percent }\end{array}$ \\
\hline PIU nominal & Normal & 6400 & 61.1 \\
PIL nominal & Normal & 3400 & 60.3 \\
PIU breakout & Log-normal & 4041 & 29.8 \\
PIL breakout & Log-normal & 6216 & 29.7 \\
\hline
\end{tabular}

TABLE 2.-PHOTOVOLTAIC ARRAY MAST

STRENGTH PROPERTIES

\begin{tabular}{|c|c|c|c|}
\hline $\begin{array}{c}\text { Magt design } \\
\text { limit load, } \\
\text { in.-lb }\end{array}$ & Type & $\begin{array}{c}\text { Mean, } \\
\text { in.-lb }\end{array}$ & $\begin{array}{c}\text { Coefficient of } \\
\text { variation, } \\
\text { percent }\end{array}$ \\
\hline 8300 & Log-normal & 13750 & 16.4 \\
30700 & Log-normal & 50655 & 16.4 \\
48500 & Log-normal & 91263 & 20.6 \\
\hline
\end{tabular}


TABLE 3.-DETAILED PROBABILITY DATA OF BOTTOM LONGERON,

30,700 in.-Ib PIL ARRAY

\begin{tabular}{|l|r|c|r|r|}
\hline Variable & Mean & $\begin{array}{c}\text { Coefficient of } \\
\text { variation, } \\
\text { percent }\end{array}$ & $\begin{array}{c}\text { Deaign } \\
\text { point }\end{array}$ & $\begin{array}{c}\alpha, \\
\text { sensitivity }\end{array}$ \\
\hline Mant atrength & 50,655 & 16.4 & 31,007 & 0.5389 \\
Nominal dynamle load & 3,400 & 60.3 & 6,452 & -.2729 \\
Breakout dynamic load & 6,216 & 29.7 & 18,492 & -.7144 \\
Plume uncertainty factor & 1.0 & 10.0 & 1.157 & -.2869 \\
Model uncertainty factor & 1.0 & 6.7 & 1.075 & -.2058 \\
\hline Safety index, $\beta=5.455$ & \multicolumn{3}{|c|}{ Probability of failure, $P_{f}=2.4600 \times 10^{-8}$} \\
\hline
\end{tabular}

TABLE 4.-DETAILED PROBABILITY DATA OF BOTTOM LONGERON,

30,700 in.-Ib PIU ARRAY

\begin{tabular}{|l|r|c|c|c|}
\hline Variable & Mean & $\begin{array}{r}\text { Coefficient of } \\
\text { variation, } \\
\text { percent }\end{array}$ & $\begin{array}{c}\text { Design } \\
\text { point }\end{array}$ & $\begin{array}{c}\alpha, \\
\text { sensitivity }\end{array}$ \\
\hline Mast atrength & 50,655 & 16.4 & 28,593 & 0.6295 \\
Nominal dynamic losd & 5,400 & 61.1 & 15,728 & -.6731 \\
Breakout dynamic load & 4,041 & 29.8 & 6,584 & -.3328 \\
Plume uncertainty factor & 1.0 & 10.0 & 1.179 & -.3286 \\
Model uncertainty factor & 1.0 & 6.7 & 1.087 & -.2378 \\
\hline Safoty index, $\rho=5.461$ & \multicolumn{3}{|c|}{ Probablity of failure, $\mathrm{P}_{\mathrm{f}}=2.3743 \times 10^{-8}$} \\
\hline
\end{tabular}

TABLE 5.-PROBABILITY OF FAILURE SUMMARY FOR THREE

MAST CAPABILITIES

\begin{tabular}{|c|l|l|l|l|}
\hline $\begin{array}{c}\text { Maat deaign } \\
\text { limit load, } \\
\text { in.-lb }\end{array}$ & \multicolumn{1}{|c|}{$\begin{array}{c}P_{n} \\
\text { upper array }\end{array}$} & $\begin{array}{c}P_{n} \\
\text { lower array }\end{array}$ & \multicolumn{1}{c|}{$\begin{array}{c}P_{n} \\
\text { either array }\end{array}$} & $P_{f}$ \\
\hline Ilfetime \\
8,300 & 0.567 & 0.467 & 0.769 & 1.00 \\
30,700 & $4.64 \times 10^{-8}$ & $2.37 \times 10^{-8}$ & $1.00 \times 10^{-8}$ & $1.20 \times 10^{-8}$ \\
48,500 & $2.86 \times 10^{-12}$ & $8.84 \times 10^{-12}$ & $1.17 \times 10^{-11}$ & $1.40 \times 10^{-0}$ \\
\hline
\end{tabular}




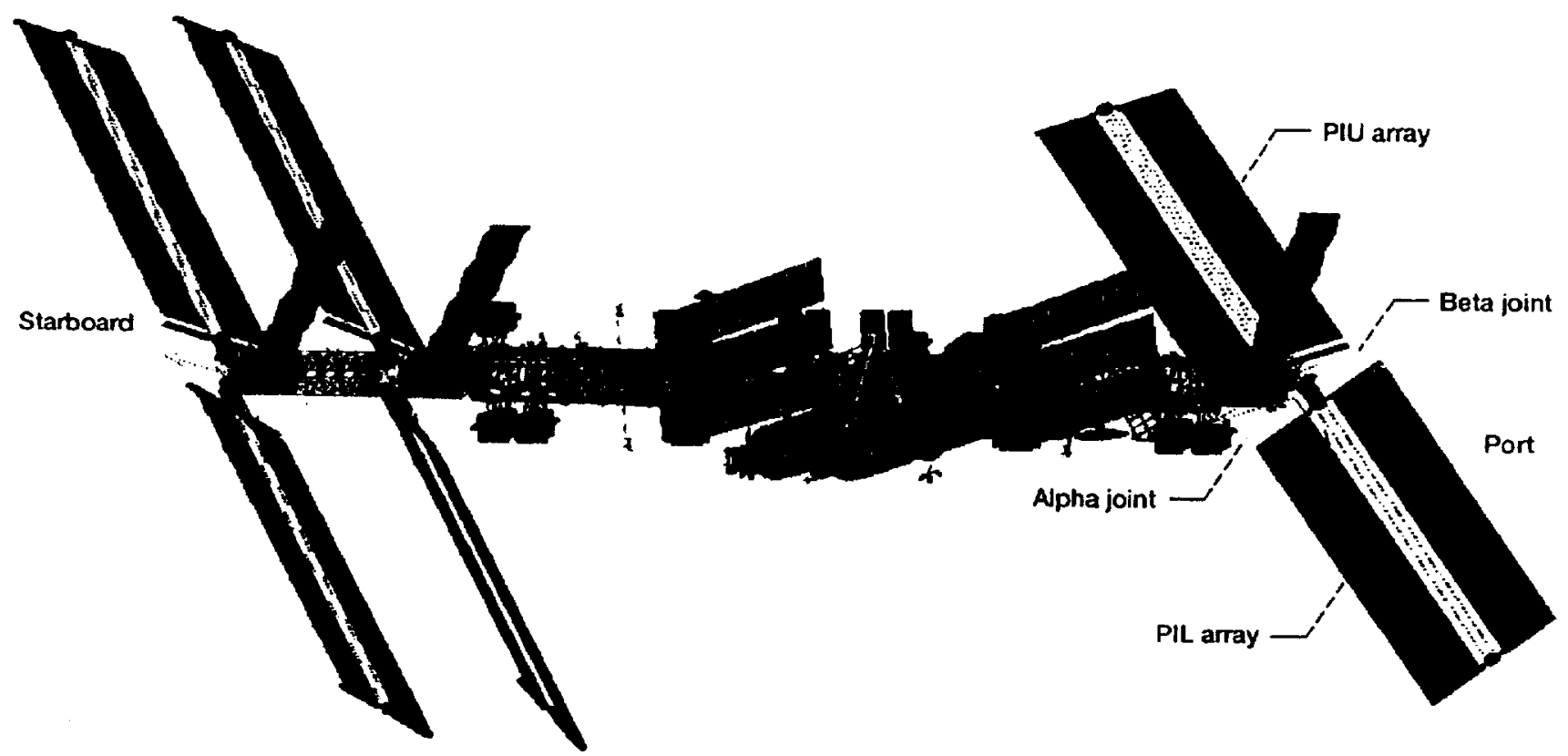
Figure 1.-Permanently manned configuration (PMC) of the space station with feathered photovoltaic arrays. Port alpha $=-44^{\circ}$,
PIU beta $=-22^{\circ}$, PIL beta $=-48^{\circ}$.

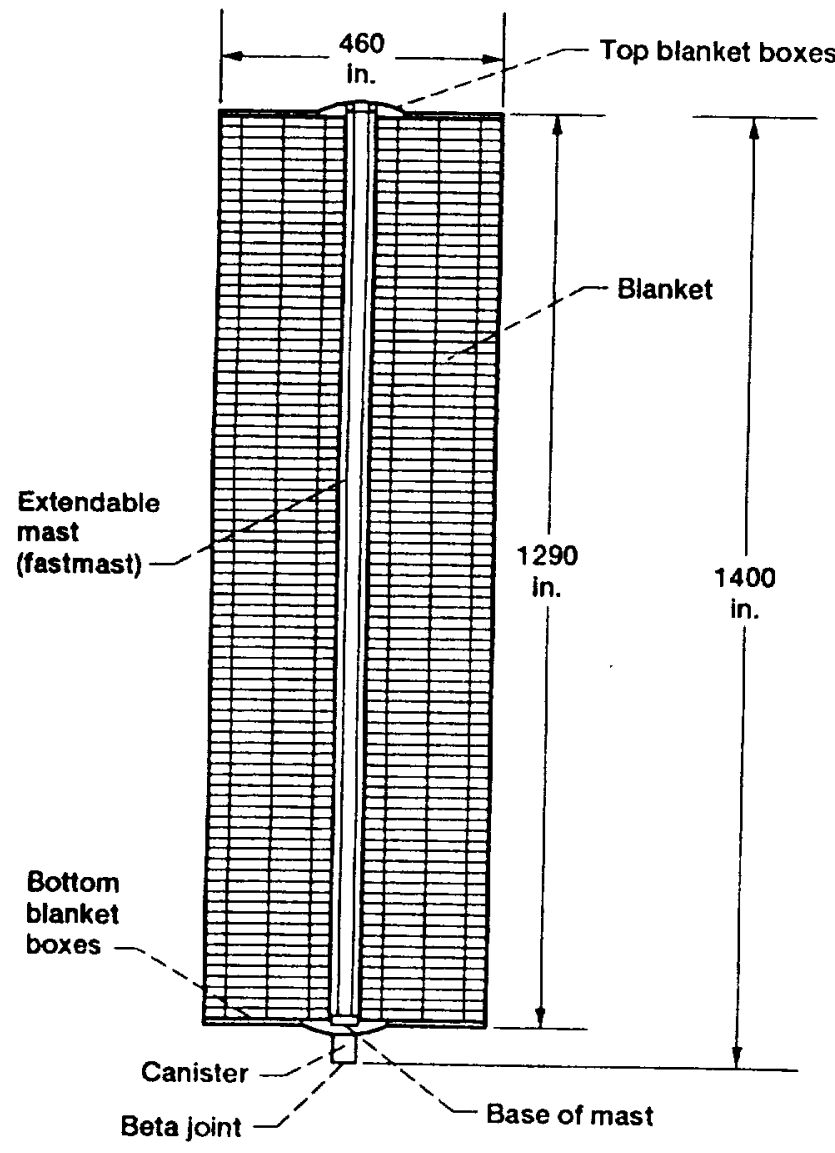

Figure 2.-Space Station Freedom photovoltaic array.

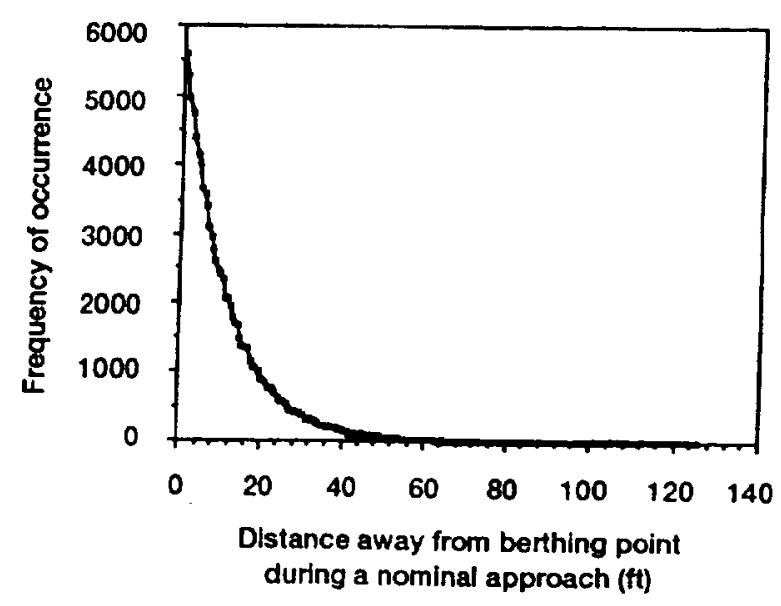

Figure 3.-Frequency of occurrence of distance away from the space station when the jets were fired during the Monte Carlo simulations of the nominal approach. 


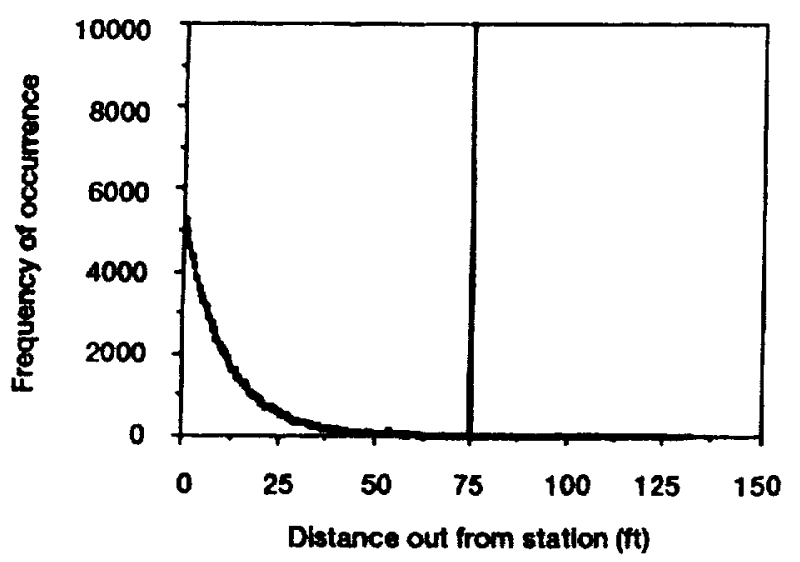

Figure 4.-Frequency of occurrence of distance away from the space station when the jets were fired during the Monte Carlo simulations of the breakout maneuver.

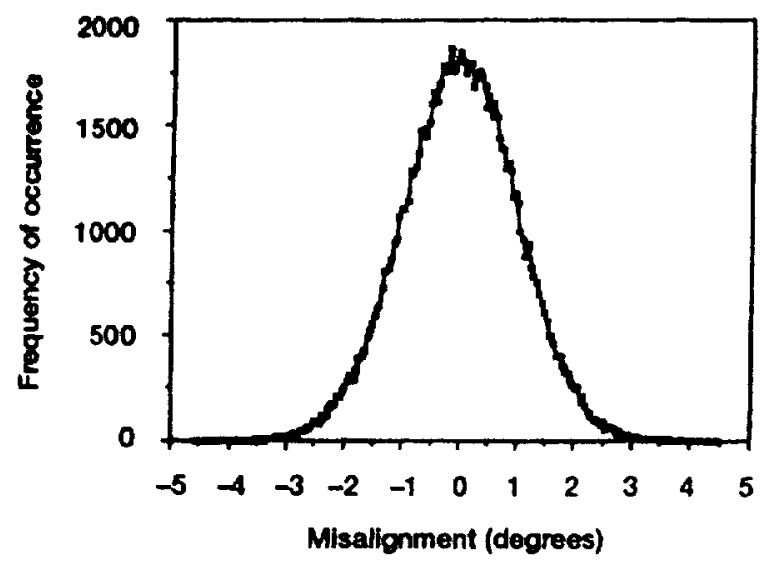

Figure 6.-Frequency of occurrence of shuttle rotation about $X, Y$, and $Z$ axes when lets were fired in the Monte Carlo simulations. Distribution is designed as normal with a mean $=0, \sigma=1.0^{\circ}$.

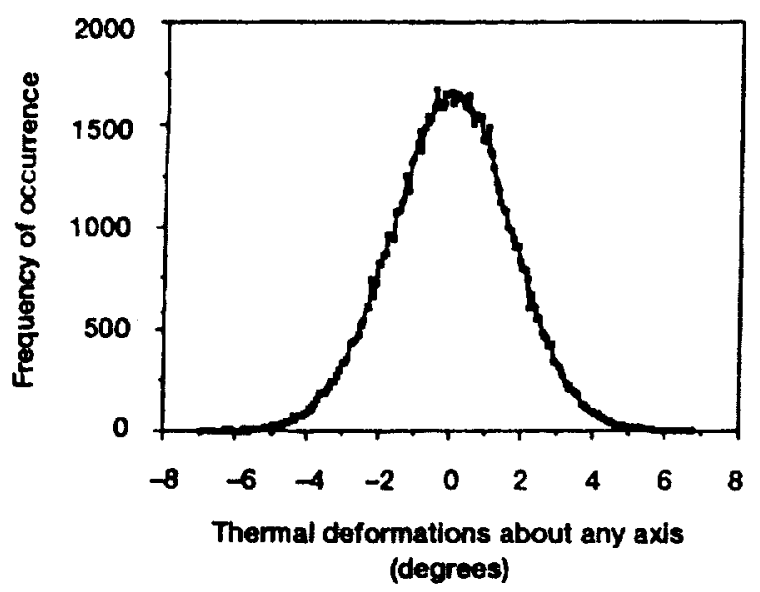

Flgure 8.-Frequency of occurrence of thermal twist deformations about $X, Y$, and $Z$ axes when jets were fired in the Monte Carlo simulations. Distribution is designed as normal with a mean $=0,0=1.67^{\circ}$.

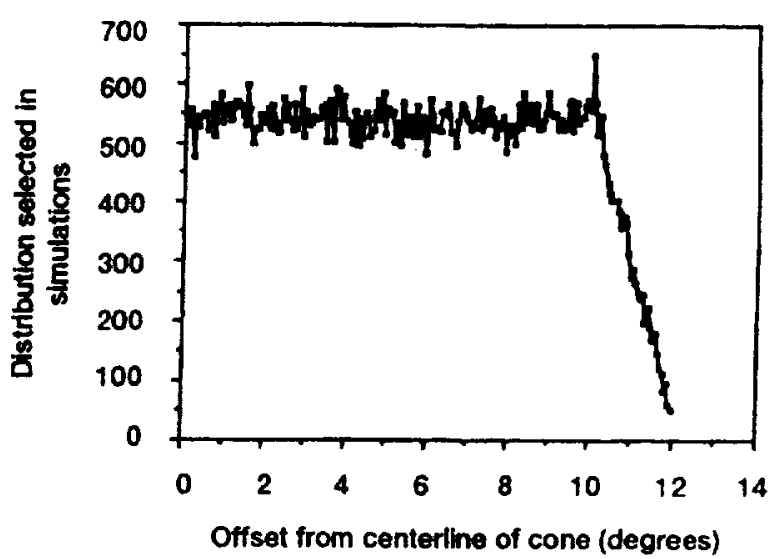

Floure 5.-Distribution of radial offset from the centerline of the cone of approach when jets were fired in the Monte Carlo simulations. Distribution is designed as uniform inside of $\pm 10^{\circ}$ and decreasing linearty to zero at $12.2^{\circ}$.

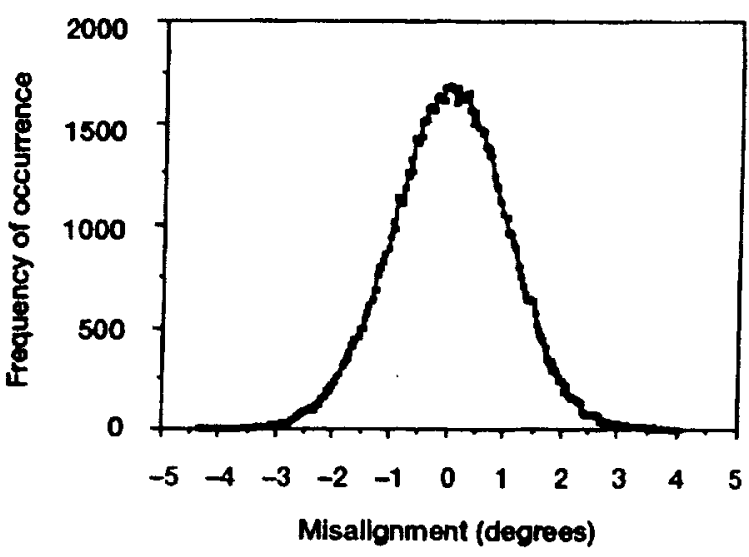

Figure 7.-Frequency of occurrence of space station rotation about $X, Y$, and $Z$ axes when jets were fired in the Monte Carlo simulations. Distribution is designed as normal with a mean $=0, \sigma=1.0^{\circ}$.

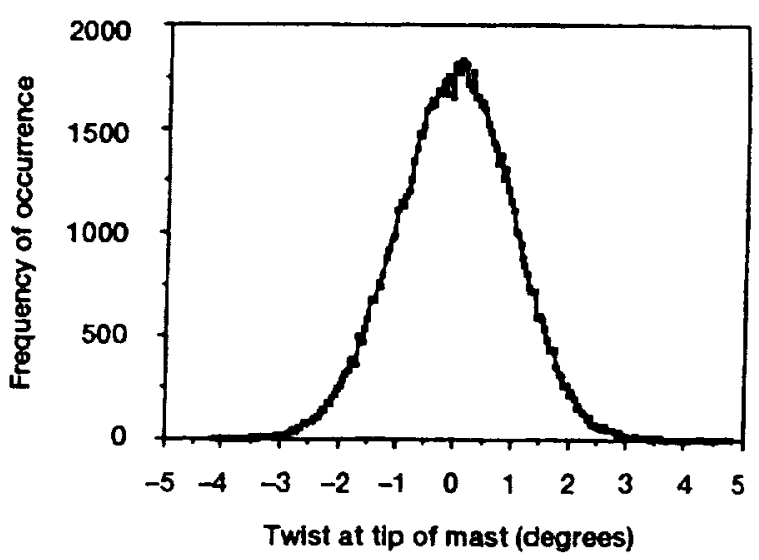

Figure 9.-Frequency of occurrence of mast design twist when jets were fired in the Monte Carlo simulations. Distribution is designed as normal with a mean $=0$, $\sigma=1.0^{\circ}$. 


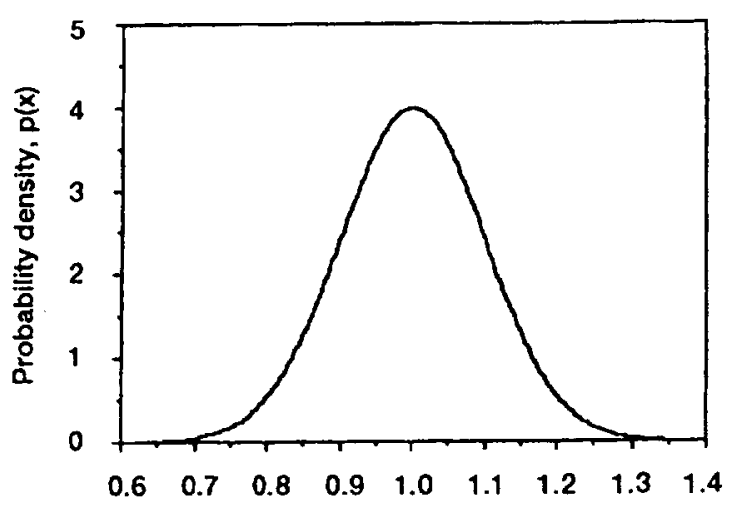

Plume force prediction uncertainty factor

Figure 10.-Distribution of the uncertalnty factor on the plume impingement force prediction used in the limit state function. Normal distribution with mean $=1.0$, $\sigma=0.1$.

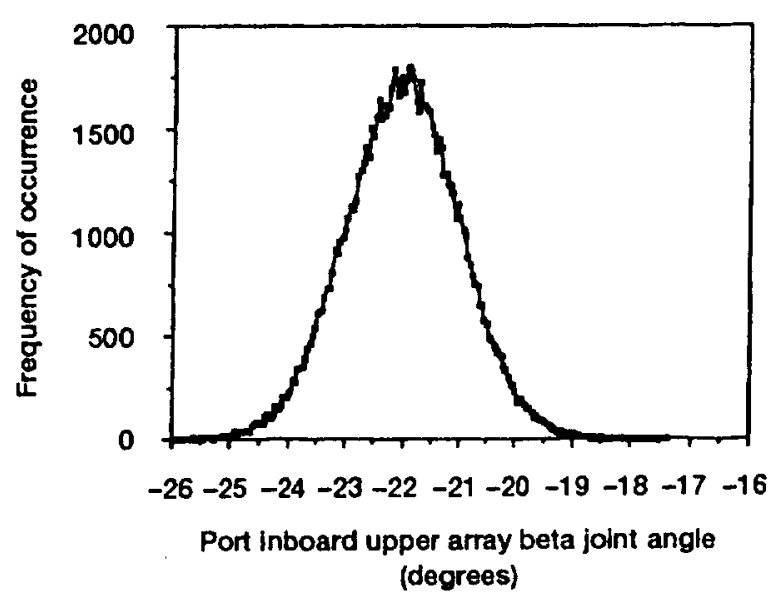

Figure 12.-Frequency of occurrence of port inboard upper photovoltalc array beta jolnt angles selected when jets were fired during the Monte Carlo simulations. Distribution is designed as normal with a mean $=-22^{\circ}$, $\sigma=1.0^{\circ}$.

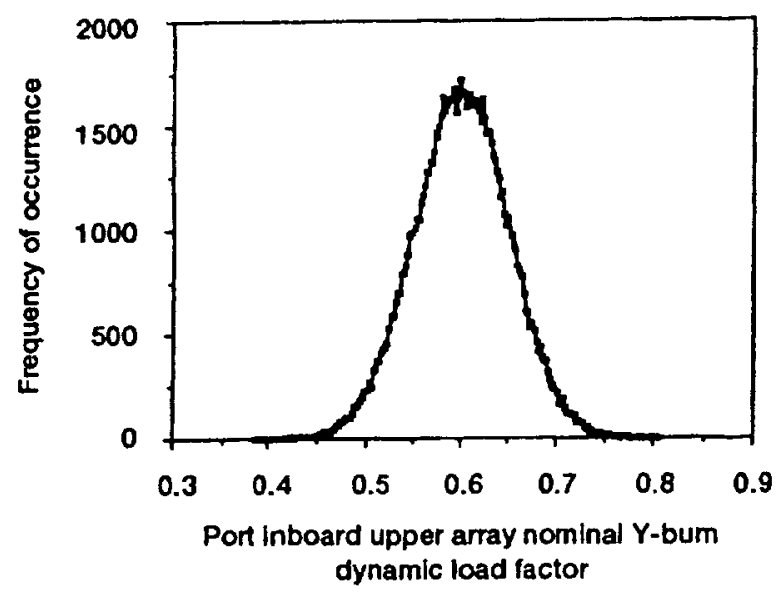

Figure 14.-Frequency of occurrence of dynamic load factor on the port inboard upper photovoltaic array due to $Y$-bum flrings during a nominal approach. Distribution is designed as normal with a mean $=0.6, \sigma=0.05$.

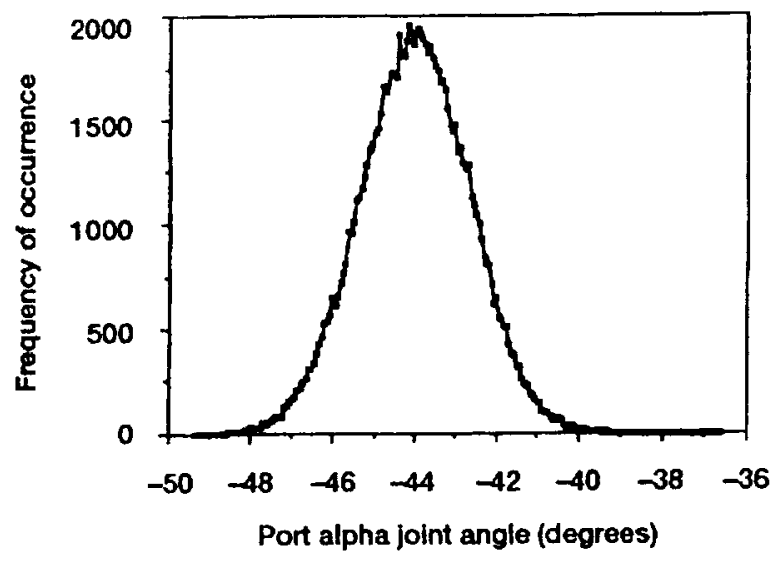

Flgure 11. - Frequency of occurrence of port alpha joint angles selected when lets were fired during the Monte Carlo simulations. Distribution is designed as nomal distribution with mean $=-44^{\circ}, \sigma=1.333^{\circ}$.

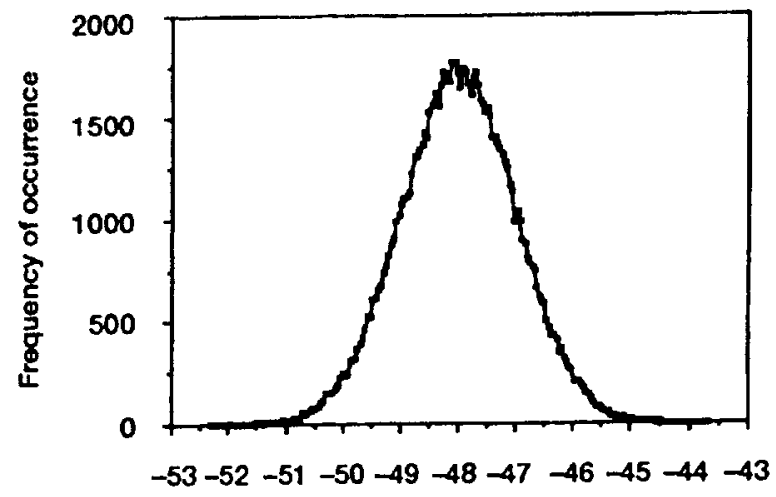

Port inboard lower beta joint angle (degrees)

Figure 13.-Frequency of occurrence of port inboard lower photovoltaic array beta joint angles selected when lets were fired during the Monte Carlo simulations. Distribution is desłgned as normal with a mean $=-48^{\circ}$, $\mathrm{\sigma}=1.0^{\circ}$

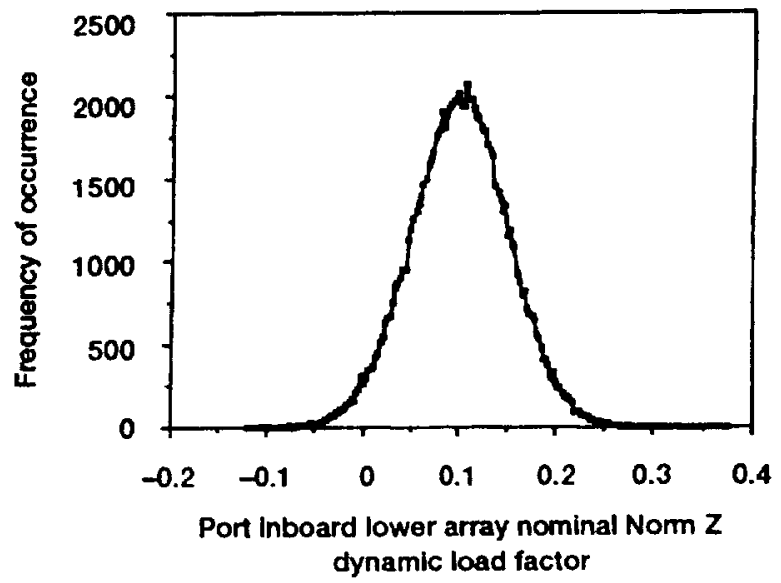

Flgure 15.-Frequency of occurrence of dynamlc load factor on the port inboard lower photovoltalc array due to Z-braking firings during a nominal approach. Distribution is designed as normal with a mean $=0.1, \sigma=0.05$. 


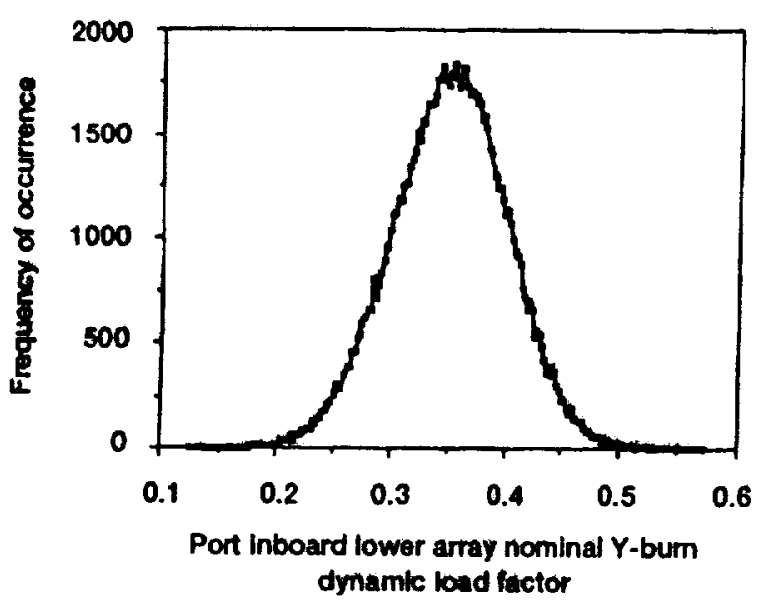

Floure 16.-Frequency of occurrence of dynamlc load factor on the port inboard lower photovoltalc stray due to Y-bum firings during a nominal approach. Distribution is designed as normal with a mean $=0.35, a=0.05$.

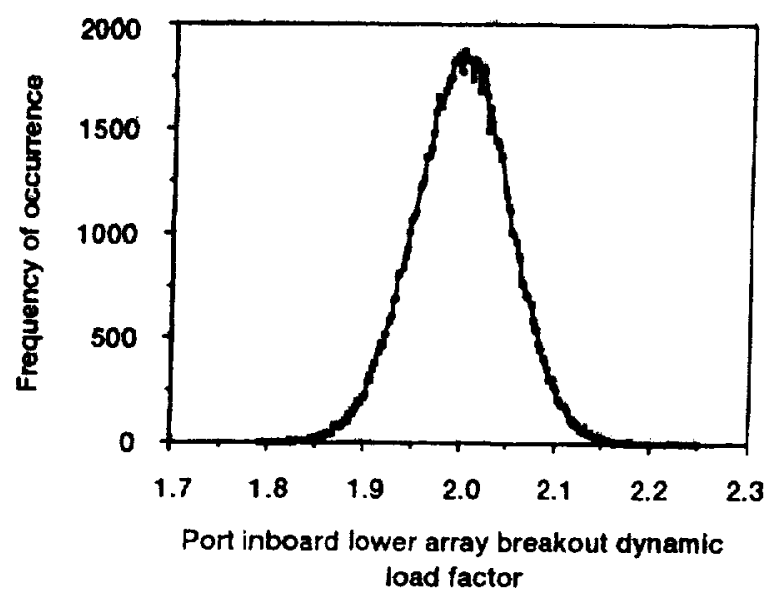

Figure 18.-Frequency of occurrence of dynamic load factor on the port inboard lower photovoltaic array due to a Norm Z breakout. Distribution is designed as normal with a mean $=2.0, \sigma=0.05$.

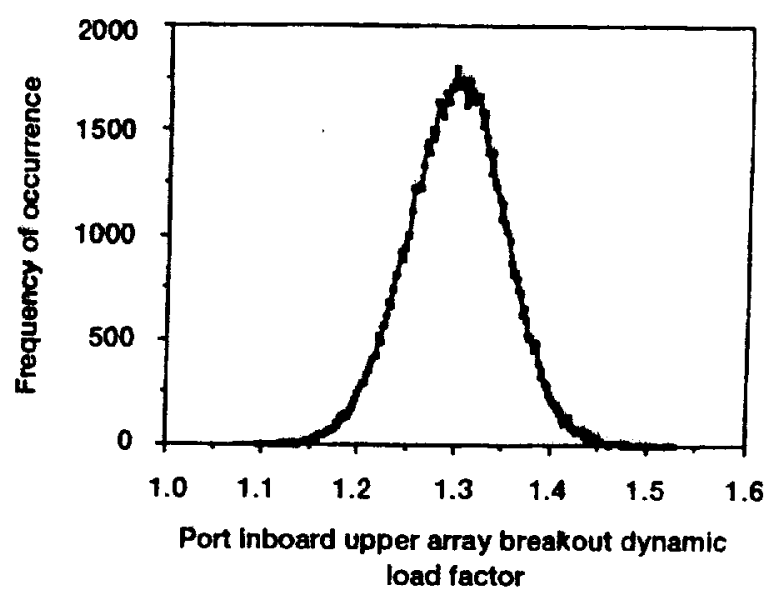

Figure 17.-Frequency of eccurrence of dynamic load factor on the port inboard upper photovoltaic array due to a Norm Z breakout. Distribution is designed as normal with a mean $=1.3, \sigma=0.05$.

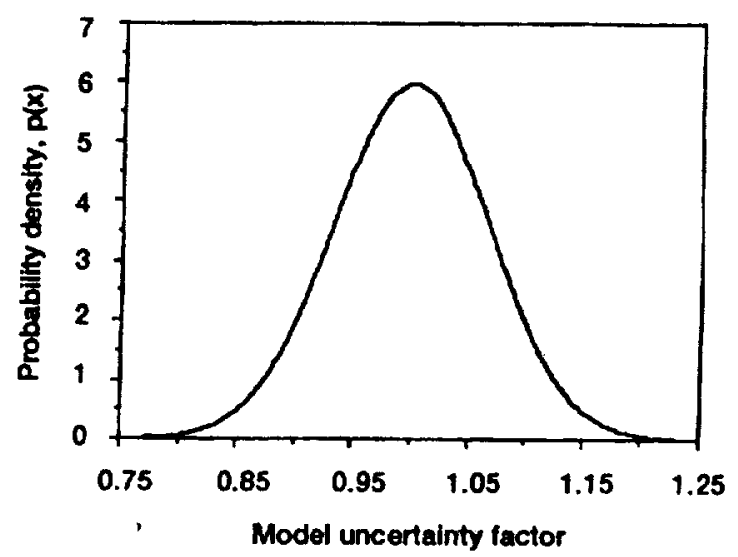

Figure 19.-Distribution of model (dynamics) uncertainty factor used in the Monte Carlo simulations. Normal distributions with a mean $=1.0,0=0.0667$. 


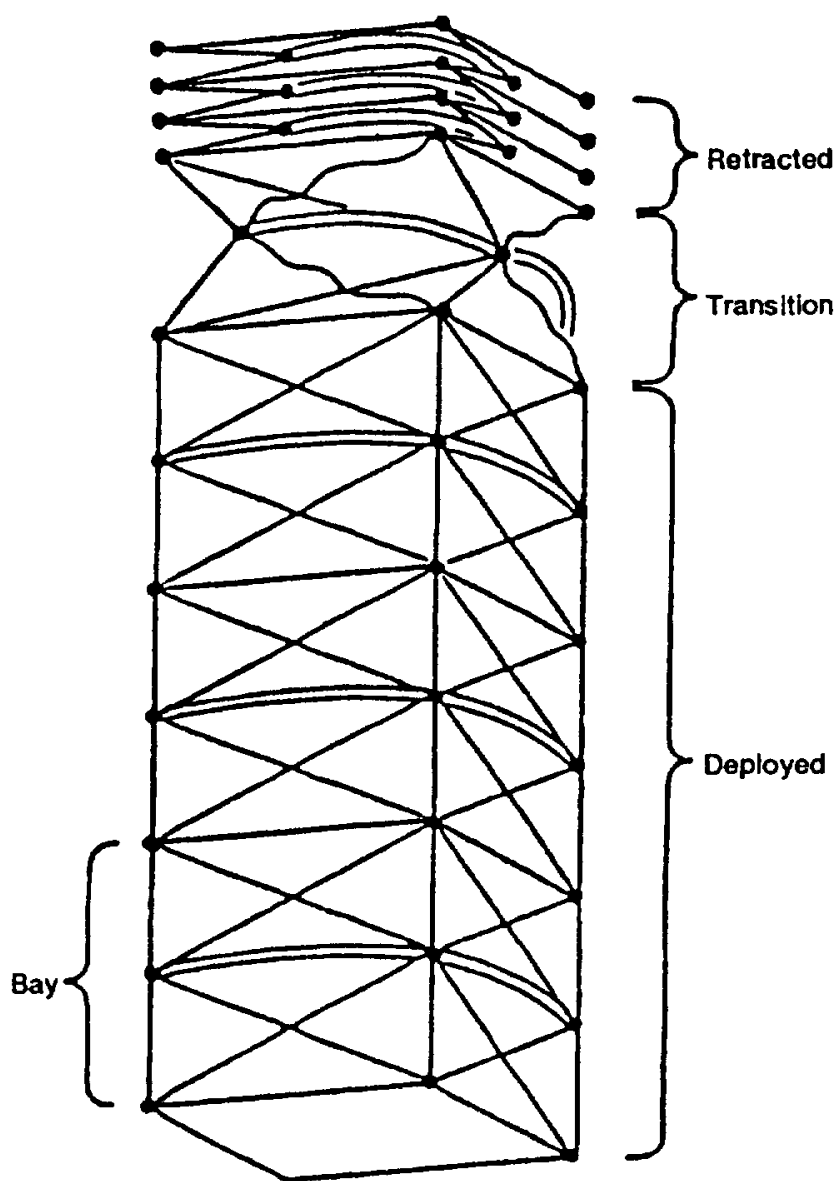

Figure 20.-Photovoltaic array deployable mast.

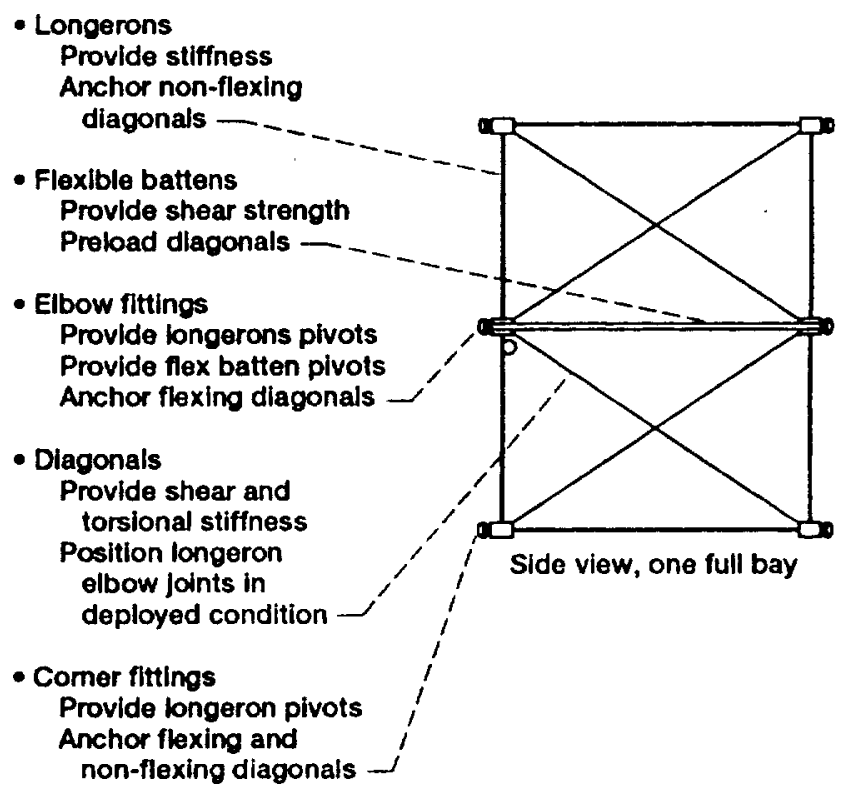

Figure 21.-Details of deployable mast. 


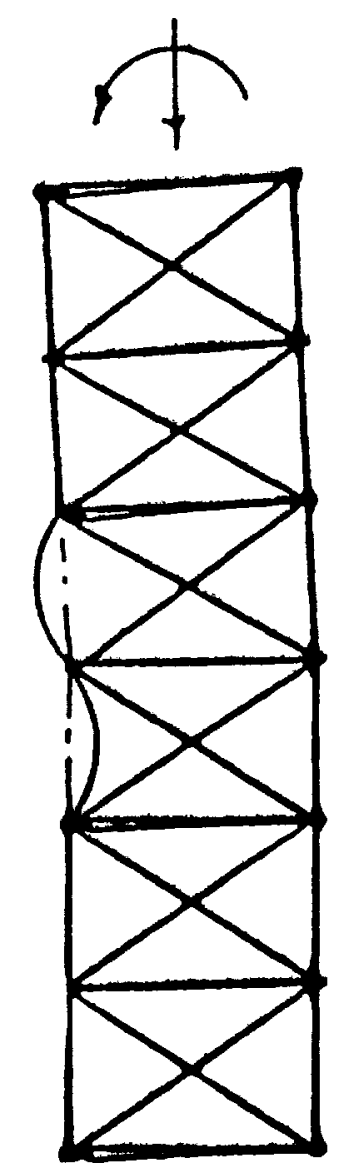

Flgure 22.-Primary fallure mode of the deployable mast (Euler Buckling).

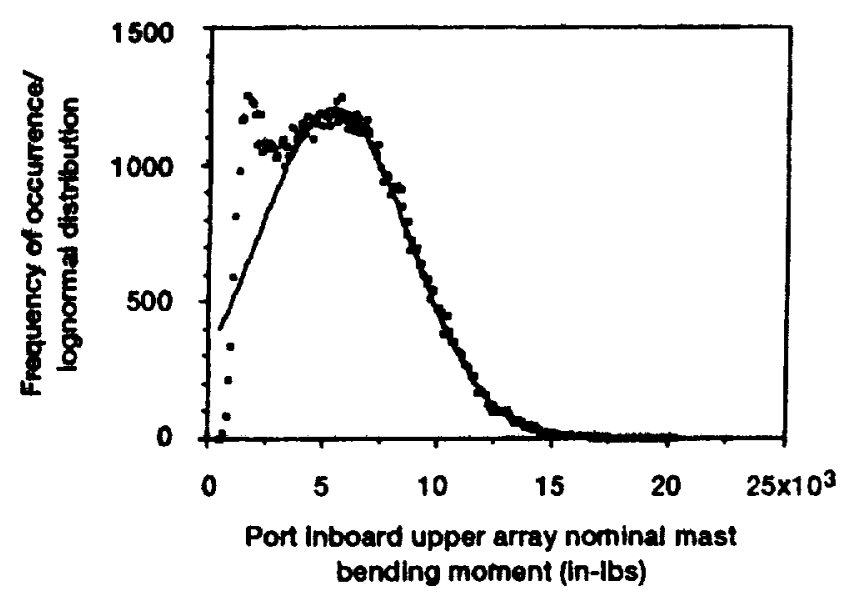

Figure 24.-Distribution of nominal approach bending moment on the port inboard upper photovoltalc array. The data points represent the results of the Monte Carlo simulations. The curve is the normal distribution used as a model for the data.

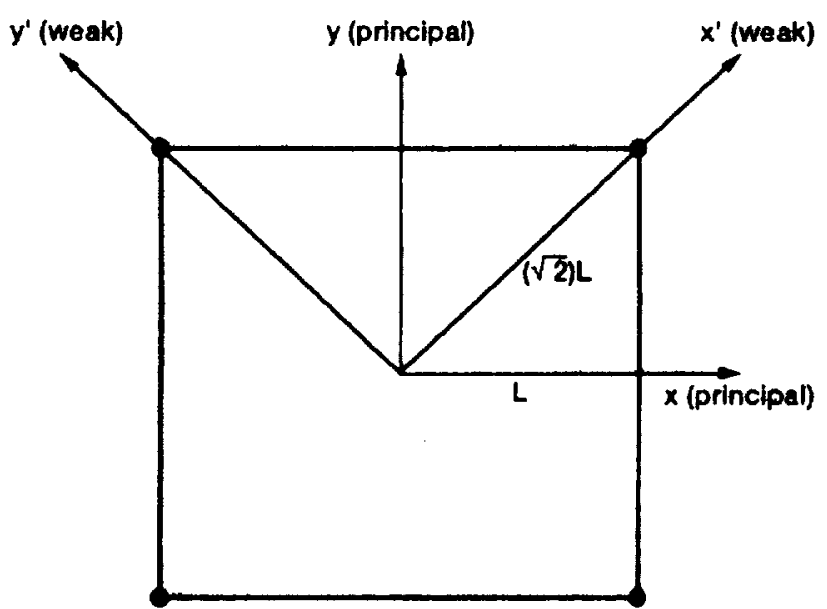

Figure 23.-Top view of deployable mast.

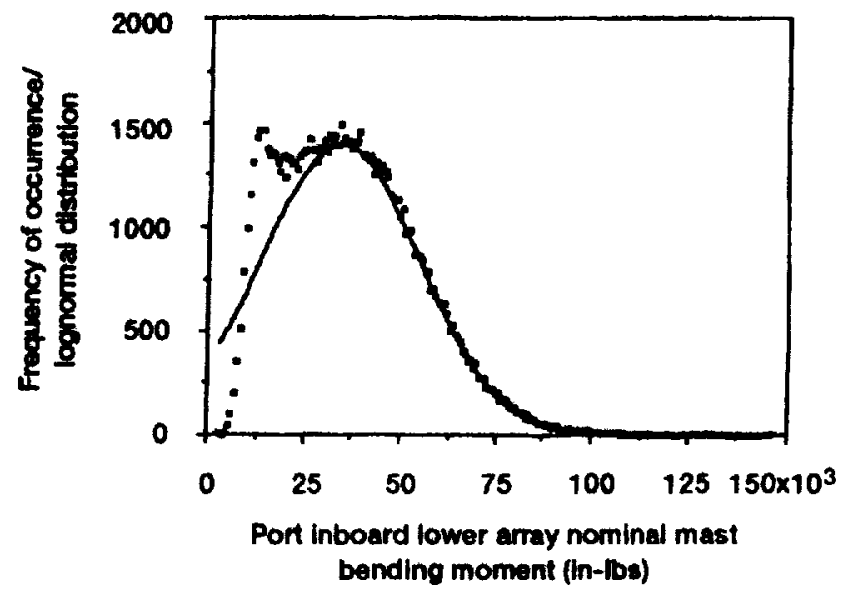

Figure 25.-Distribution of nominal approach bending moment on the port inboard lower photovoltalc array. The data points represent the results of the Monte Carlo simulations. The curve is the normal distribution used as a model for the data. 


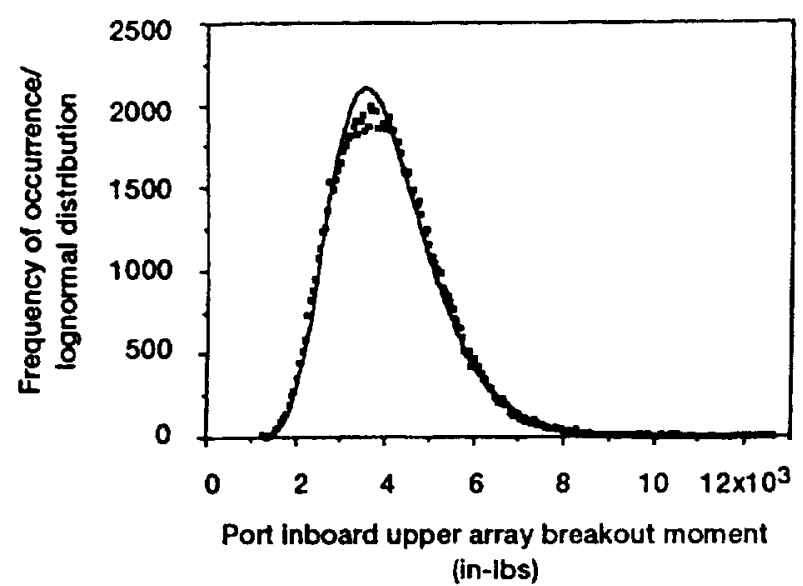

Figure 26.-Distribution of breakout induced bending moment on the port inboard upper photovoltaic amay. The data points represent the results of the Monte Carlo simulations. The curve is the log-normal distribution used as a model for the data.

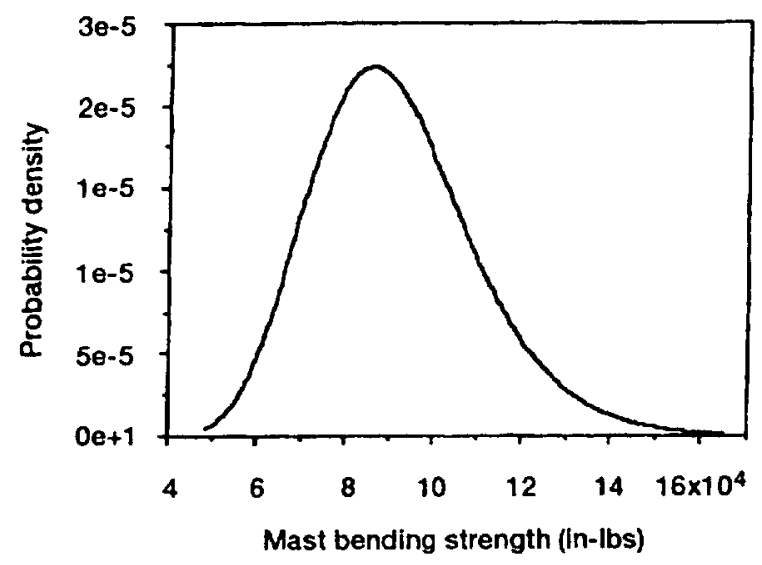

Figure 28. - Log-normal distribution representing the bending strength of the photovoltalc array mast. This curve is for the mast with listed strength of 48500 in-lbs.

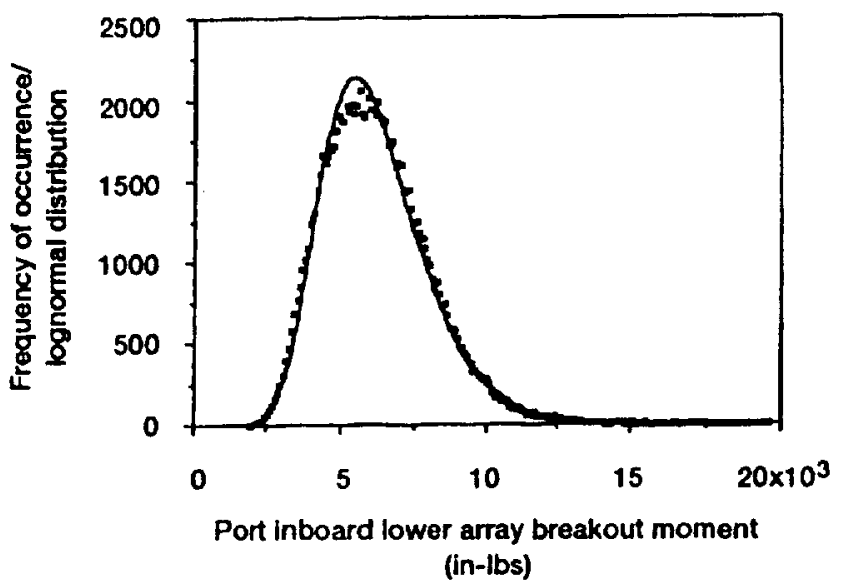

Figure 27.-Distribution of breakout induced bending moment on the port inboard lower photovoltalc array. The data points represent the results of the Monte Carlo simulations. The curve is the log-normal distribution used as a model for the data.

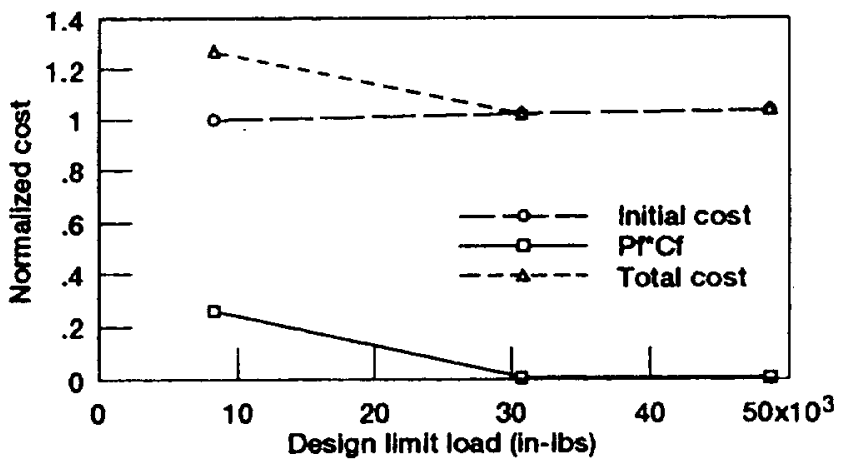

Figure 29.-Design load of the SSF photovoltalc array versus cost, normalized by original initial cost, Co. 


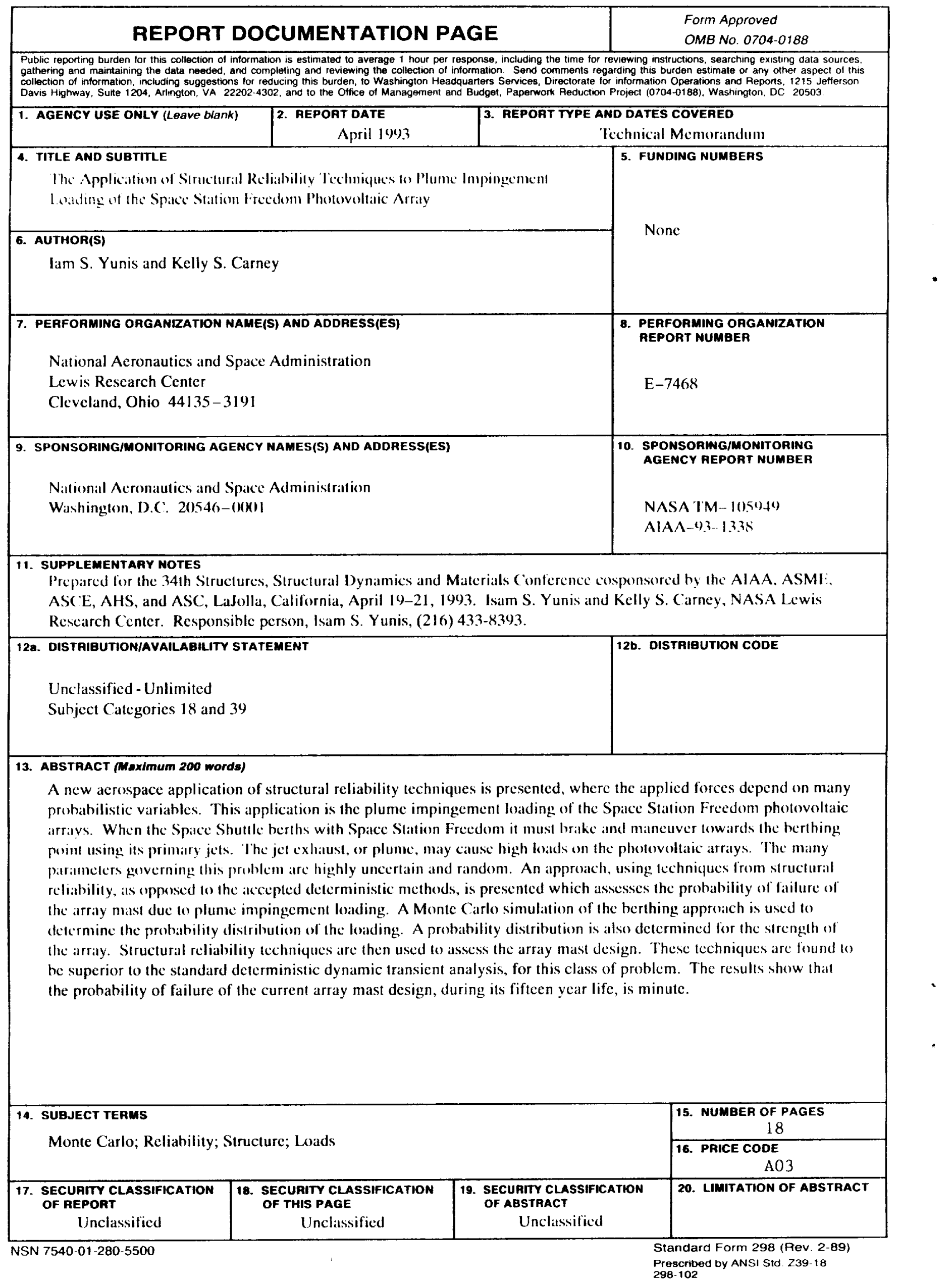


National Aeronautics and

Space Administration

Lewis Research Center

Cleveland, Ohio 44135

Omaled Businece

Peneiry tor Privite Une 2000
FOUATH CLASS MANL

ADORESS COARECTION REOUESTED

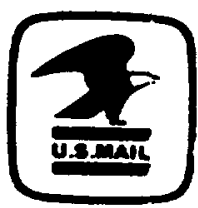

Poslage and $F$ zes Pald

National Aeronaulics and

Space Adminisiralocon

NASA 451 
